\title{
Bevacizumab/Cetuximab Regimen
}

National Cancer Institute

\section{Source}

National Cancer Institute. Bevacizumab/Cetuximab Regimen. NCI Thesaurus. Code C37553.

A chemotherapy regimen consisting of bevacizumab and cetuximab that may be used in the treatment of colorectal cancer. 